\title{
TV shows on Light Pollution Education for the Public
}

\author{
Valentin Grigore ${ }^{1,2}$ \\ ${ }^{1}$ Societatea Astronomic Romn de Meteori (Romanian Society for Meteors and Astronomy), \\ Str. Tineretului nr. 1, Trgovite 130020, Dmbovia, Romania sarm.ro@gmail.com \\ ${ }^{2}$ Noi i Cerul (Us ans the Sky) TV show, Columna TV, Romania
}

\begin{abstract}
TV shows have the biggest impact for the public, so we can use them to inform and educate the public about light pollution and the importance of the dark sky for humanity and for the contemporary society. Some examples used in the TV show Us and the Sky at Columna TV, Romania, are presented.
\end{abstract}

Keywords. Light Pollution, Citizen Science, Public Outreach

As you saw on TV! Could we use this phrase when talking about light pollution? Visual impact is most effective for education. The subject of light pollution should be a part of regular TV programming, not only on specialized TV channels. The role of TV:

A. TO INFORM Provide fair and complete information! 1. About light pollution. It affects directly the quality of our life (health, budget, comfort, and security), the world climate, wildlife and the natural night sky and our right to see the stars, the astronomy and research. 2. Ways to combat light pollution. It is not necessary to turn off the public illumination. We just need to streamline it and light responsibly! Suggestion: Invite onto TV shows specialists from different fields: doctors, biologists, ecologists, astronomers, city managers, tourism workers, politicians (for LP laws), etc.

B. TO EDUCATE How does light pollution appear? Who is responsible for that? What do we need to do to combat light pollution? Suggestions: 1. Use common objects to explain the effects of the LP. See: http://www . youtube.com/watch?v=GfzXLzeuo2A 2. Use animations and cartoons. We need more good multimedia resources, easy to understand by the public and even by children. IAU, IDA, NASA, ESO and others should create more short multimedia products (video, animations) to be used in TV shows. See: http://planetgreen.discovery.com/videos/my-place-starry-night.html

C. TO ADVERTISE the global efforts to combat light pollution. The global campaigns such as GLOBE at Night, Earth Hours, Dark-Sky Week, World Night in Defence of the Starlight, GAM, etc. Dedicated meetings and conferences: IAU SpS17, European Symposium for the Protection of the Dark Sky, Dark-sky Parks, etc. Suggestions: 1. Make these events as important TV News subjects. 2. Invite journalists and workers of public and state institutions at all important dark-sky events.

D. TO STRESS night sky and astronomy importance for humanity, for culture and progress. Suggestions: 1 . Show practical aspects of astronomy (calendar, navigation, communications even mobile phones!). 2. Delight people with spectacular views of the night sky! 3. Use space music, astrofolk music, cosmopoetry.

In the future we should have partnerships with media institutions, including TV. A TV Network with affiliates in every IAU country is useful. Dark-sky and light pollution campaigns should create more video spots and contacts with local TVs. Noi si Cerul (Us and the Sky) is a weekly TV show produced by Valentin Grigore,President of the Romanian Society for Meteors and Astronomy (SARM) at Columna TV, a Romanian TV channel, streaming live online via Internet at http://www. columnatv.ro/tv. 